\title{
The impact of 10 years of human papillomavirus (HPV) vaccination in Australia: what additional disease burden will a nonavalent vaccine prevent?
}

\author{
${\text { Cyra Patel }{ }^{1} \text {, Julia ML Brotherton }}^{2,3}$, Alexis Pillsbury¹, Sanjay Jayasinghe ${ }^{1,4}$, Basil Donovan ${ }^{5,6}$, Kristine Macartney ${ }^{1,4}$, Helen \\ Marshall 7,8 \\ 1. National Centre for Immunisation Research and Surveillance, Westmead, Australia \\ 2. VCS Population Health, VCS Foundation, East Melbourne, Australia \\ 3. School of Population and Global Health, University of Melbourne, Parkville, Australia \\ 4. Discipline of Child and Adolescent Health, Faculty of Medicine and Health, University of Sydney, Sydney, Australia \\ 5. The Kirby Institute, University of New South Wales, Sydney, Australia \\ 6. Sydney Sexual Health Centre, Sydney Hospital, Sydney, Australia \\ 7. Vaccinology and Immunology Research Trials Unit, Women's and Children's Hospital, North Adelaide, Australia \\ 8. Robinson Research Institute and Adelaide Medical School, University of Adelaide, North Adelaide, Australia
}

Correspondence: Cyra Patel (cyra.patel@health.nsw.gov.au)

Citation style for this article:

Patel Cyra, Brotherton Julia ML, Pillsbury Alexis, Jayasinghe Sanjay, Donovan Basil, Macartney Kristine, Marshall Helen. The impact of 10 years of human papillomavirus (HPV) vaccination in Australia: what additional disease burden will a nonavalent vaccine prevent?. Euro Surveill. 2018;23(41):pii=1700737. https:// doi.org/10.2807/1560-7917.ES.2018.23.41.1700737

Background: A National human papilloma virus (HPV) Vaccination Programme for the prevention of HPV infection and associated disease using the quadrivalent HPV vaccine (4vHPV) has been funded and implemented in Australia since 2007, initially for girls only and extended to boys in 2013, with uptake rates among the highest observed worldwide. Aim: We report on the impact of this national programme on HPV prevalence and associated disease burden and estimate the potential impact of adopting a nonavalent HPV (9vHPV) vaccine. Methods: We performed a non-systematic literature review of studies measuring the burden of HPV-associated disease and infection in Australia before and after introduction of HPV vaccination. We also included key national reports with estimates of HPV-related disease burden. Results: Substantial declines in high-grade cervical disease and genital warts among vaccine-eligible women have been observed. Reductions in genital warts incidence and HPV prevalence among heterosexual men of similar age were observed before introduction of the male vaccination programme, indicating a substantial herd effect. 9VHPV vaccine is expected to prevent up to $90 \%$ of cervical and $96 \%$ of anal cancers. Of an estimated 1,544 HPV-associated cancers in 2012, 1,242 would have been preventable by the $4 \mathrm{VHPV}$ vaccine and an additional 187 anogenital cancers by the 9vHPV vaccine. Conclusions: Vaccination using 4VHPV vaccine has had a large demonstrable impact on HPV-related disease in Australia. A switch to 9vHPV could further reduce the HPV-associated cancer burden. With continued high coverage among both males and females, elimination of vaccine-type HPV disease seems achievable in Australia.

\section{Background}

Human papillomavirus (HPV) infections result in a substantial burden of disease globally as cervical cancer, anogenital and oropharyngeal malignancies and anogenital warts in both men and women. Vaccination for the prevention of HPV infection has been available for more than a decade. In 2007, Australia became one of the first countries to fund and implement a National HPV Vaccination Programme. The ongoing schoolbased programme for girls (aged 12-13 years) and a community-based programme for women up to the age of 26 years (that concluded in 2009) have used a 3 -dose schedule of the quadrivalent HPV vaccine Gardasil (4VHPV vaccine), which protects against HPV types $6,11,16$ and 18 . In 2013, the funded programme was expanded to boys (aged 12-13 years, with catchup for 14-15-year-olds available till end-2014), making Australia one of 22 countries and territories (including nine countries in Europe, namely Austria, Croatia, the Czech Republic, Germany, Italy, Liechtenstein, Norway, Switzerland and, most recently, the United Kingdom) that have implemented or announced their intention to implement a gender-neutral HPV vaccination programme. From January 2018, a 2-dose course of the nonavalent HPV vaccine Gardasil 9 (9vHPV vaccine), which targets 4VHPV types plus HPV 31, 33, 45, 52 and 58 , replaced the $4 \mathrm{VHPV}$ programme.

Given the changing approaches to HPV disease prevention in Australia, we provide an overview of the current 
Estimates of genital HPV prevalence among sexually active women aged 18-24 years, by HPV type, Australia, 2005-2012 $(\mathrm{n}=1,260)$

\begin{tabular}{|c|c|c|c|c|}
\hline \multirow[t]{2}{*}{ HPV type } & \multirow{2}{*}{$\begin{array}{l}\text { Pre-vaccination era }(2005-07) \\
\qquad(\mathrm{n}=202)\end{array}$} & \multicolumn{3}{|c|}{$\begin{array}{l}\text { Post-vaccination era (2010-12) } \\
\qquad(n=1,058)\end{array}$} \\
\hline & & $\begin{array}{l}\text { Overall population } \\
\text { prevalence }\end{array}$ & $\begin{array}{l}\text { Prevalence in } \\
\text { vaccinated }\end{array}$ & $\begin{array}{l}\text { Prevalence in } \\
\text { unvaccinated }\end{array}$ \\
\hline HPV 6 & $5.5 \%$ & $0.9 \%$ & $0.2 \%$ & $2.7 \%$ \\
\hline HPV 11 & $1.5 \%$ & $0.4 \%$ & $0 \%$ & $1.3 \%$ \\
\hline HPV 16 & $21.3 \%$ & $4.2 \%$ & $1.5 \%$ & $12.1 \%$ \\
\hline HPV 18 & $8.4 \%$ & $1.9 \%$ & $0.6 \%$ & $7.4 \%$ \\
\hline $\mathrm{HPV}_{31}$ & $5.0 \%$ & $4.0 \%$ & $2.7 \%$ & $8.1 \%$ \\
\hline HPV 33 & $4.0 \%$ & $1.5 \%$ & $1.4 \%$ & $2.0 \%$ \\
\hline HPV 45 & $1.0 \%$ & $2.6 \%$ & $1.7 \%$ & $6.0 \%$ \\
\hline HPV 52 & $7.4 \%$ & $8.2 \%$ & $6.9 \%$ & $9.4 \%$ \\
\hline HPV 58 & $5.5 \%$ & $3.4 \%$ & $3.9 \%$ & $2.7 \%$ \\
\hline HPV 6/11 & $6.9 \%$ & $1.3 \%$ & $0.2 \%$ & $4.0 \%$ \\
\hline HPV $16 / 18$ & $26.2 \%$ & $5.4 \%$ & $2.1 \%$ & $16.1 \%$ \\
\hline HPV 31/33/45 & $9.4 \%$ & $7.8 \%$ & $5.6 \%$ & $14.8 \%$ \\
\hline 4VHPV types ${ }^{\mathrm{a}}$ & $28.7 \%$ & $6.5 \%$ & $2.3 \%$ & $18.8 \%$ \\
\hline High-risk HPV types ${ }^{b}$ & $47.0 \%$ & $34.9 \%$ & $34.4 \%$ & $44.3 \%$ \\
\hline All HPV types & $59.9 \%$ & $48.8 \%$ & $49.4 \%$ & $55.7 \%$ \\
\hline
\end{tabular}

HPV: human papillomavirus.

Data were obtained from Figure 1 and Table 4 of a paper reporting results of the Vaccine Impact in the Population study, where cervical specimens were obtained from women attending family planning clinics in three states [18]. Overall prevalence data were calculated manually using the information in Table 4 of the original publication.

a 4 VHPV types include HPV types 6, 11, 16 and 18 .

${ }^{\mathrm{b}}$ High-risk types include HPV types $16,18,31,33,35,39,45,51,52,56,58,59$ and 68.

epidemiology of HPV-associated disease from multiple Australian data sources. We also report on the progress made in the decade following commencement of the National HPV Vaccination Programme, and provide an estimate of the further impact achievable.

\section{Methods}

We performed a non-systematic review of the published literature to identify recent epidemiological studies that measured the burden of HPV-associated disease and infection in Australia. We searched the Medline and Embase databases for studies published from January 2007 to April 2016 using key search terms related to disease outcome measures, including papillomavirus infection, genital warts or condylomata acuminanata, cancers, carcinomas and neoplasms associated with HPV (including cervical, vulvar, vaginal, anus, penile, mouth, oropharyneal and laryngeal) and recurrent respiratory papillomatosis. Searches were limited to studies in humans and those that included 'Australia' as a text word. We selected articles that measured the prevalence or incidence of HPV-associated disease and infection before and after introduction of the vaccination programme, focusing on publications from 2014 onwards to indicate contemporary HPV disease burden estimates. In addition to articles identified through the searches, our review included data from publications since April 2016 that the authors were aware of. Reports from the Australian Institute of Health and Welfare (AIHW) were reviewed to report the documented incidence of HPV-associated cancers and cervical disease burden nationally and to estimate the disease burden preventable with HPV vaccination. We calculated the incremental benefit of the 9VHPV vaccine (on top of the $4 \mathrm{VHPV}$ vaccine) by applying the proportion of cases attributable to 9v-non4VHPV types, reported in the published literature, to the number of HPV-attributable cancer cases.

\section{The burden of HPV-associated cancers in Australia}

\section{Cervical cancer}

Following the implementation of the National Cervical Screening Programme (NCSP) in 1991, the incidence rate of cervical cancer in Australia decreased from ca 18 to 6-7 per 100,00o between 1991 and 2002 and has since plateaued for over a decade, reported at 7.4 per 100,000 women in 2014 [1]. Similarly, cervical cancer mortality rates in women aged 20-69 years halved from 4.0 to 2.0 per 100,000 between 1991 and 2002, tapering off thereafter and reported at 1.8 per 100,000 in 2015 [1]. Aboriginal and Torres Strait Islander women (hereafter called 'Indigenous women') have historically 
Trends in high-grade cervical abnormalities in women by age group before and after commencement of the female HPV vaccination programme, Australia, 2004-2014

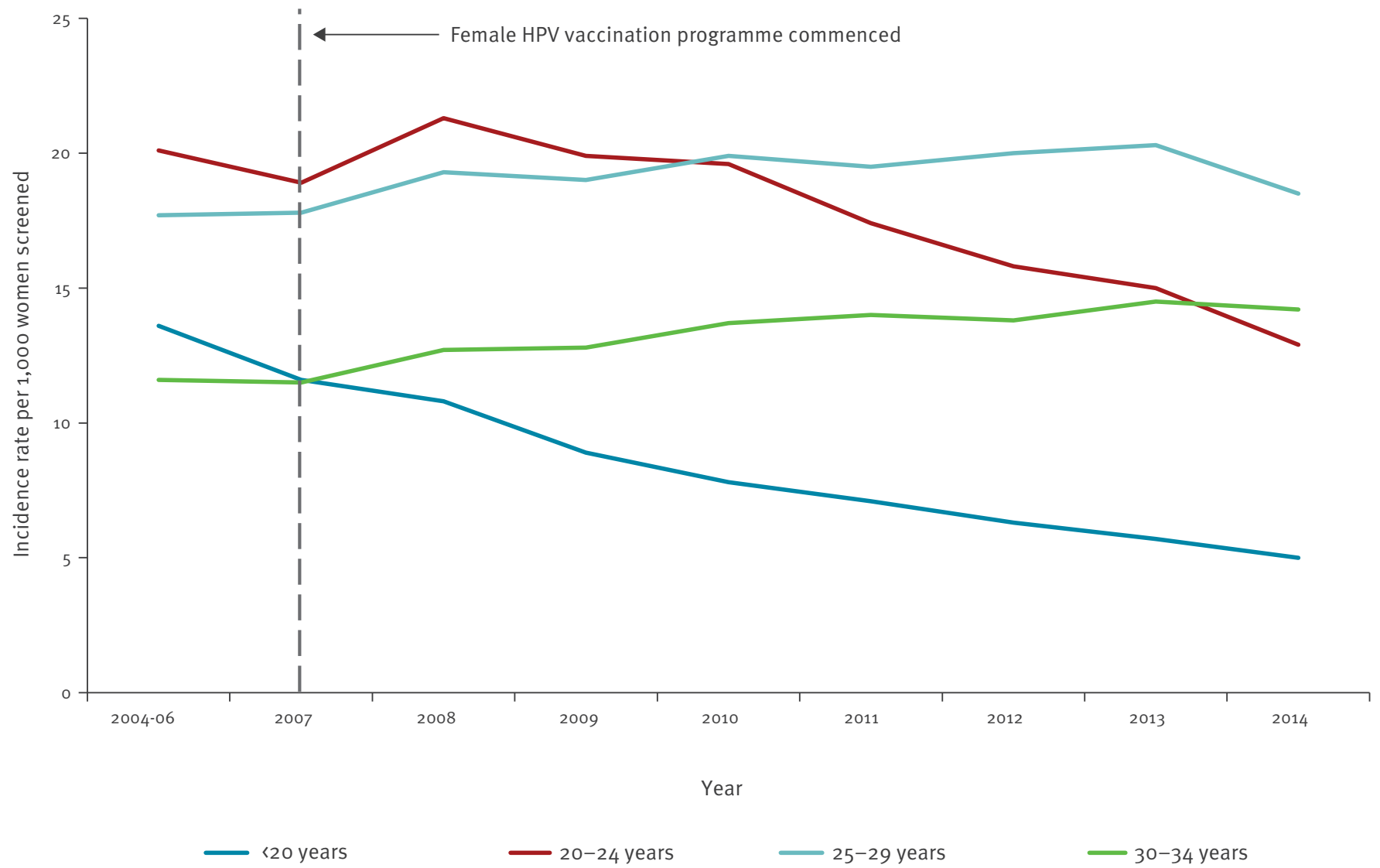

HPV: human papillomavirus.

Source: Australian Institute of Health and Welfare, 2016. Cervical screening in Australia 2013 to 2014 [25].

borne a disproportionate disease burden, with incidence and mortality rates between 2011 and 2015 being approximately two and four times higher, respectively, compared with non-Indigenous women, largely owing to poorer access to cervical screening and disease treatment [1]. However, this disparity has reduced over time; a study of women in the Northern Territory found a decline in cervical cancer incidence among Indigenous women compared with non-Indigenous women between the periods 1991-1996 and 20072012 (44.4 vs 15.6 per 100,000 for Indigenous women, compared with 17.8 vs 9.9 per 100,000 for non-Indigenous women) [2].

\section{Anal cancer}

In contrast with trends in cervical cancer rates, anal cancer incidence increased in Australia between 1982 and 2005 by $3.4 \%$ and $1.9 \%$ per annum on average in men and women, respectively [3], although absolute incidence rates in 2012 were still low at 1.8 and 1.4 per 100,000, respectively [4]. Men who have sex with men (MSM) have an increased risk of anal cancer, with elevated prevalence rates of high-risk HPV types reported among MSM, especially among those with human immunodeficiency virus (HIV) [5]. Anal HPV infection was very common among MSM 18 years or older $(n=316)$ in a study in Sydney in 2005 (overall: 79\%; HIV-negative: 70\%; HIV-positive: 94\%) [6]. Prevalence of a high-risk HPV type was 5.5-fold higher in HIV-positive men compared with HIV-negative men (73\% vs 44\%; p <0.0001) [6]. In a sample of older MSM (35 years or older, $\mathrm{n}=606$ ) in Sydney enrolled between 2010 and 2015, prevalence of any anal HPV type was 94.5\% in HIV-positive men and $82.2 \%$ in HIV-negative men, with the prevalence of 9VHPV types being $60.2 \%$ and $72.6 \%$, respectively [7].

\section{Other HPV-associated cancers}

Cancers of the penis, vagina and vulva are rare in Australia and have varying proportions attributable to HPV (50\%, 70\% and 40\%, respectively [8]), with their progression from HPV infection to cancer being less well understood than that for cervical cancer [9]. While vulval cancer typically affects older women (older than 
TABLE 2

Proportion of cervical disease attributable to vaccine-targeted HPV types, Australia

\begin{tabular}{|l|c|c|c|}
\hline HPV type & High-grade cervical abnormalities & Cervical cancer $(95 \% \mathrm{Cl})$ & HPV-positive cervical cancerc $(95 \% \mathrm{CI})$ \\
\hline 16 & $51-60.3 \%[20,70-72]$ & $51.6 \%(48.2-55.0)$ & $56.0 \%$ \\
\hline 18 & $5-15 \%[20,70-72]$ & $19.6 \%(17.0-22.4)$ & $21.5 \%$ \\
\hline 31 & $11-15.8 \%[20,70,72]$ & $2.5 \%(1.5-3.8)$ & $2.7 \%$ \\
\hline 33 & $7.8-11 \%[20,70]$ & $4.3 \%(3.0-5.8)$ & $4.6 \%$ \\
\hline 45 & $3.0-6.4 \%[70]$ & $5.0 \%(3.6-6.6)$ & $5.5 \%$ \\
\hline 52 & $11.2-18.1 \%[20,70]$ & $2.4 \%(1.4-3.6)$ & $2.5 \%$ \\
\hline 58 & $5.8-8.8 \%[70]$ & $0.6 \%(0.2-1.4)$ & $0.6 \%$ \\
\hline $16 / 18$ & $57.2-65.7 \%[20,70-72]$ & $71.8 \%(68.5-74.7)$ & $77.1 \%(74.0-80.0)$ \\
\hline $31 / 33 / 45 / 52 / 58$ & Unknown & $14.8 \%(12.4-17.3)$ & $15.9 \%(13.4-18.6)$ \\
\hline 9 vHPV types & Unknown & $86.4 \%(83.9-88.7)$ & $93.0 \%(91.0-94.7)$ \\
\hline
\end{tabular}

$\mathrm{Cl}$ : confidence interval; HPV: human papillomavirus.

ancludes: Adenocarcinoma in situ and cervical intraepithelial neoplasia grade 2 or 3.

${ }^{b}$ Obtained from the Australian Cervical Cancer Typing Study (ACCTS) [40]. These data are for all cervical cancers typed ( $=847$ ). HPV was not detected in all specimens, which may be due to failure of detection following integration of HPV DNA, assay failure, misclassification of uterine cancers as cervical cancer or rarely to true HPV-negative cancers.

'Obtained from the Australian Cervical Cancer Typing Study (ACCTS) [40]. These data are for HPV-positive cervical cancers typed ( $=787$ ). The proportion of HPV-positive cervical cancers attributable to the individual 9vHPV types was calculated manually using data from Table 1 in Brotherton et al. [40]. As such, $95 \%$ Cls are not available for these proportions. The following formula was used, using HPV 16 as an example: [number of specimens with HPV 16 alone (single HPV genotype) + number of specimens with HPV 16 and other HPV types (multiple HPV genotypes)] / total number of HPV-positive cervical cancers.

70 years) [8], incidence rates in Australia are highest in women younger than 50 years residing in the Northern Territory, where rates greater than 50 times the national rate have been reported among Indigenous women aged 18-49 years residing in Arnhem Land between 1996 and 2005 (31.1 per 100,000 vs 0.4 per 100,000 nationally) [10]. Incidence of vaginal cancer in Australia has remained unchanged for the past two decades, with risk increasing with age [8].

While tobacco and alcohol are important risk factors for head and neck cancers, HPV causes a significant proportion of oropharyngeal and, to a lesser extent, oral cancers. Although still uncommon (1.0 per 100,000 in women and 4.0 per 100,000 in men), the incidence of HPV-related oropharyngeal cancers has steadily increased over the past few decades among both men and women by an estimated 1\% per year from 1982 to $2005[8,11,12]$. An analysis of 515 Australian oropharyngeal squamous cell carcinoma (SCC) specimens collected between 1982 and 2010 found that 42.7\% were HPV-positive, with the proportion of HPV-positive specimens increasing from $20.2 \%$ to $63.5 \%$ during the study period [13]. Rates of all oral cavity cancers in Australia nationally decreased between 1994 and 2008 , although one study in Queensland found incidence rates to be stable among women $[11,14,15]$.

\section{The impact of the quadrivalent HPV vaccination programme in Australia}

\section{HPV prevalence}

Among young women, the population prevalence of HPV, particularly 4VHPV types, has declined since the introduction of the National HPV Vaccination
Programme (Table 1) [16-20]. A sentinel site comparative study (Vaccine Impact in Population (VIP) Study) of women aged 18-24 years attending clinics for Pap testing reported that the $4 \mathrm{VHPV}$-type prevalence declined from $28.7 \%$ before the vaccination programme from 2005 to 2007 to $2.3 \%$ in vaccinated women ( $p<0.0001$ ) from 2010 to 2012 [18]. Infections were more common in unvaccinated women or women vaccinated after sexual debut [19]. More recent evidence from sentinel family planning clinics in Victoria and New South Wales (NSW) in 2015 indicates declines in 4VHPV prevalence in women aged $25-35$ years [21]. No decline in 4vHPVtype prevalence was found among women aged 18-24 years born overseas in countries with substantially lower levels of vaccination [16]. These results are consistent with those of a global meta-analysis of seven studies on HPV prevalence (including the VIP study), which found a $68 \%$ decline in HPV $16 / 18$ infection in countries with vaccination coverage of at least $50 \%$ [22].

Declines in HPV prevalence have also been observed among men. Although most men do not seroconvert after exposure to HPV, persistent infections are associated with seroconversion. A retrospective HPV DNA analysis of stored urine and urethral specimens from heterosexual men 25 years and younger who were positive for chlamydia found that the prevalence of $4 \mathrm{VHPV}$ types declined between 2004 and 2015 (pre-vaccination: $18 \%$, 95\% confidence interval (Cl): 12-25; postvaccination: $7 \%, 95 \% \mathrm{Cl}: 5-9$; adjusted prevalence ratio: $0.37,95 \% \mathrm{Cl}: 0.22-0.60, \mathrm{p}<0.0001$ ) [23]. Two HPV serosurveys among men in three states (NSW, Queensland and Victoria) demonstrated a decrease in the seroprevalence of $4 \mathrm{VHPV}$ types in men aged 20-39 

years between 2005 and 2012-13 [24]. As the National HPV Vaccination Programme only became available to boys in 2013, these declines are likely to be due to a herd effect derived from the female vaccination programme.

\section{Cervical disease}

Decreases in the incidence rates of high-grade cervical abnormalities (HGAs) in vaccine-eligible age cohorts of women are well documented by Australia's cervical screening registers at both state and national levels. The greatest and earliest decline in HGA incidence occurred among the youngest age group ( $<20$ years) who, by 2014 , had a rate of 5.0 per 1,000 women screened nationally, less than half the rate in 2007 [25]. By 2011 and 2014, national incidence was also declining in women aged 20-24 years and 25-29 years, respectively (Figure) [25].

A linkage study using data from the Victorian Cervical Cytology Registry and the National HPV Vaccination Programme Register showed that incidence of HGAs among vaccine-eligible women (aged 12-17 years in 2007) who completed vaccination was lower than among unvaccinated women (4.1 and 6.4 per 1,000 screened, respectively, in 2011) [26]. Further analysis including women aged up to 26 years showed vaccination to be protective against both high-grade histological and cytological abnormalities (vaccine effectiveness of $14 \%$ and $47 \%$, respectively, calculated as 1 - adjusted hazard ratio), with the protective effect of partial vaccination becoming more apparent with increasing time since vaccination [27]. A linked analysis of data from vaccination and screening registers in Queensland demonstrated a similar impact with estimated vaccine effectiveness against histologically confirmed $\mathrm{HGAs}$ at $46 \%(95 \% \mathrm{Cl}: 33-57)$ and against other cervical abnormalities at $34 \%(95 \% \mathrm{Cl}: 30-38)$ among women attending for their first cervical screen [28]. Greater benefits of vaccination are anticipated in the future, as more cohorts of fully vaccinated girls and boys younger than 15 years (i.e. before sexual debut) become older.

\section{Genital warts}

Genital warts are often emotionally distressing to the patient and treatment can be long and painful, with a proportion of cases occurring recurrently. Although only a minority of genital warts require hospital treatment, estimates before commencement of HPV vaccination indicate a substantial overall number of hospitalisations [29]. The impact of the HPV Vaccination Programme on reducing genital warts incidence in Australia has been the greatest globally to date [22] and is largely attributable to the extensive catch-up programme [30], with the biggest reductions observed in young women eligible for the school-based vaccination programme [31-36]. The proportion of Australian-born patients diagnosed with genital warts at the Melbourne Sexual Health Clinic decreased from $13.1 \%$ to $5.7 \%$ between 2004 and 2014, with more substantial decreases observed for younger women ( 21 years) [36]. Relative to 2006-07, national hospitalisation rates related to genital warts in 2010 and 2011 declined by $89.9 \%$ (95\% $\mathrm{Cl}: 84.6-93.4), 72.7 \%(95 \% \mathrm{Cl}: 67.0-77.5)$ and $42.1 \%$ (95\% Cl: 26.1-54.6) in females aged $12-17,18-26$ and 27-30 years, respectively, with no significant change for women aged 31-69 years [29]. Similarly, data from Medicare (the national public health insurance scheme for all residents in Australia) on in-patient treatment for genital warts in private hospitals showed an $85 \%$ decline from 2007 to 2011 in women aged 15-24 years [35]. Notably, hospitalisation rates declined by $86.7 \%$ (95\% Cl: 76.0-92.7) in Indigenous women aged 15-24 years compared with $76.1 \%$ ( $95 \% \mathrm{Cl}: 71.6-79.9)$ in nonIndigenous women of the same age [29]. Similarly, large declines in the incidence rates of genital warts were observed in the period after commencement of vaccination (2008-14 vs 2004-07) among young Indigenous women and teenagers $(12-20$ years: rate ratio $(R R)=0.12, \quad p<0.001 ; 21-30$ years: $R R=0.41$, $p<0.001)$ and men $(12-20$ years: $R R=0.25, p<0.001$; 21-30 years: $R R=0.56, p=0.016$ ) attending sexual health clinics [37], demonstrating the potential of vaccination to minimise the disparity in HPV-associated disease burden between Indigenous and non-Indigenous women.

A substantial herd effect on genital warts from the female vaccination programme has been observed in young unvaccinated heterosexual males [34]. Hospitalisations associated with genital warts in 2010 and 2011 declined among men aged $18-26$ and $27-30$ years relative to those in 2006 and 2007 (38.3\%; 95\% $\mathrm{Cl}: 27.8-47.2$ and $21.2 \%$; $95 \% \mathrm{Cl}: 0.8-37.4$, respectively), with no significant changes for males in other age groups [29]. Among men attending the Melbourne Sexual Health Clinic, genital wart diagnoses decreased from $11.3 \%$ in 2004 and 2005 to $2.8 \%$ in 2013 and 2014 among those younger than 21 years and from $19.1 \%$ to $5.9 \%$ among 21-32-year-olds [36].

\section{Juvenile-onset recurrent respiratory papillomatosis}

Juvenile-onset recurrent respiratory papillomatosis (JORRP) is a rare condition that develops in childhood, which is acquired via vertical transmission of HPV 6 or 11 and can be associated with significant morbidity and mortality [38]. Recent evidence indicates that the incidence of JORRP in Australia has declined from 0.16 per 100,000 in 2012 to 0.02 per 100,000 in 2016 $(p=0.034)$, with none of the cases' mothers reporting HPV vaccination pre-pregnancy [39].

\section{How much more disease can be prevented in the future using a nonavalent vaccine?} Given the long latency period between HPV infection and progression to cancer, the full impact of HPV vaccination on rates of HPV-associated cancers is yet to be seen. A recent analysis of more than 800 invasive cervical cancer cases in women aged 20-99 years (median: 50 years) from seven pathology laboratories 
in Queensland, NSW and Victoria from 2005 to 2015 found that HPV 16 and 18 were detected in $51.6 \%$ and $19.6 \%$ of the specimens, respectively, comprising $71.8 \%$ of all cancers [40]. The additional five oncogenic HPV types in the 9vHPV vaccine corresponded to the viruses detected in $14.8 \%$ of the specimens (Table 2 ) [40]. Therefore, the 9VHPV vaccine has the potential to prevent almost $90 \%$ of cervical cancers, or 753 (4VHPV types: 624; 9v-non4VHPV types: 129) of 869 incident cases in 2012 in Australia (Table 3).

The vast majority (up to 95\%) of anal SCCs are associated with HPV [41]. A retrospective Australian study testing 112 anal cancer specimens obtained between 1999 and 2009 reported that 90\% were caused by 4VHPV types, with HPV 16 being most commonly detected (75\%) [42]. 9vHPV types were detected in $96 \%$ of the samples, implying that nearly all HPV-associated anal cancer cases may be potentially preventable with 9vHPV vaccine [42].

Data on the proportion of penile, vaginal and vulvar cancers containing HPV by genotype are lacking in Australia, but are available from international metaanalyses. In a meta-analysis of 29 studies (mostly from North America and Europe), ca $70 \%$ of vaginal cancers were HPV-positive, with HPV 16 being the most commonly detected type (54\%) followed by HPV 18 and 31 [43]. A report from the United States (US) suggested the 9vHPV vaccine could reduce HPV-associated vaginal, vulval and penile cancers by approximately a further $18 \%, 14 \%$ and $9 \%$, respectively, beyond 4VHPV [44].

Among an Australian hospital-based sample of 248 oropharyngeal cancers, of which 50 were HPV-positive, HPV 16 and 18 were the most prevalent types (42 and five cases, respectively), with HPV 33 detected in two cases [45]. Data on the proportion of oropharyngeal cancers attributable to other 9v-non4VHPV types in Australia are not available.

We estimate that the replacement of 4VHPV vaccine with 9VHPV vaccine in the Australian vaccination programme can potentially prevent an additional $15 \%$ of cervical cancers and $11 \%$ of anal cancers (Table 3 ). Based on current incidence rates in Australia under the previous cytology-based NCSP, at least an additional 187 cases of HPV-associated anogenital cancers are preventable per annum. A further reduction in cervical cancer incidence (24-36\%) and mortality (29-36\%) rates is expected following the replacement of Pap smear testing with HPV DNA-based testing through the NCSP renewal (implemented in December 2017) [46]. Modelling of this change predicted that only two screens per lifetime would be equivalent in cancer prevention efficacy for 9vHPV vaccinated cohorts compared with current screening practice in Australia, assuming continued high vaccine coverage [47]. Within the context of this new screening programme, the 9vHPV vaccine is still expected to reduce cervical cancer incidence and mortality rates by $10 \%$ [48]. The impact on cervical cancer should start to become apparent in the next 5-10 years, even taking into account an expected observed transient increase in cervical cancer diagnoses as prevalent cases are detected following the transition of the screening programme to the more sensitive HPV-based test. For non-cervical cancers, observing a reduction in incidence may take decades due to the older mean age of onset of these cancers. With good vaccination coverage in males and females, near elimination of genital warts is expected [49].

\section{The future for Australia's National HPV Programme}

Our paper summarises the current state of HPV disease epidemiology in Australia, providing a benchmark for the evaluation of imminent changes to HPV prevention strategies. Although it is not an exhaustive literature review, we highlight the progress made by the $4 \mathrm{VHPV}$ vaccination programme and the potential gains of including the 9vHPV vaccine in the programme. Similar successes have been observed in European countries that have implemented HPV vaccination programmes, particularly those achieving similarly high coverage. Declines in vaccine-type HPV prevalence have been observed among vaccinated women in Belgium, England, Italy, the Netherlands, Norway, Scotland and Switzerland [50-54]. Even in Sweden where vaccine coverage has been low (ca $30 \%$ in girls and negligible in boys), declines in the incidence of genital warts have been observed in vaccine-eligible cohorts of women with some herd benefit to similarly aged men [55], although not to the extent observed in high-coverage countries like Australia. Decreases in genital warts incidence were greater in Belgium, where coverage was higher, and were most prominent among women who were specifically targeted by the vaccination programme [56]. In Scotland, where high coverage of the bivalent HPV vaccine (targeting HPV 16/18) has been achieved, significant reductions in diagnoses of low- and high-grade cervical abnormalities have been reported [57].

Clinical trials indicate that the 9VHPV vaccine is efficacious in the prevention of cervical, vulval and vaginal precancerous lesions and persistent infection with vaccine-type HPV [58], and that it has a good safety profile [59]. The true added value of the 9VHPV vaccine is the prevention of high-grade cervical lesions caused by the five additional HPV types. While the bivalent vaccine is also licensed in Australia and has been shown to be highly efficacious against HPV 16/18 infection with substantial cross-protection against HPV 31/33/45 [60,61], Australia has adopted the 9vHPV vaccine because of the direct protection it affords against these and additional cancer-related HPV types. It is estimated that 90.9\% of HPV infections in Europe are attributable to 9vHPV types, which is an additional $13.6 \%$ on top of the $77.3 \%$ attributable to HPV 16 and 18 [62], though these proportions may vary from country to country. Depending on the country-specific epidemiology of 
HPV, consideration of adoption of 9vHPV into existing or planned national programmes may be warranted.

The success of any HPV vaccination programme hinges on achieving and maintaining high rates of vaccine uptake among both girls and boys. The effectiveness, cost-effectiveness and overall population impact is expected to be greatest if vaccination occurs before sexual debut, thereby affording protection against HPV prior to the age at which adolescents and young adults are at highest risk of being infected $[50,63]$. HPV vaccine coverage among boys in Australia is the highest in the world, with $78 \%, 75 \%$ and $67 \%$ coverage at age 15 years for one, two and three doses, respectively, while coverage in girls is even higher $(86 \%, 83 \%$ and $78 \%$, respectively) and increasing [64]. These high coverage rates can be attributed to school-based delivery of the programme and high community acceptance of HPV vaccination as a cancer prevention strategy, with strong support for gender-neutral vaccination [65-67]. Despite the high coverage, improvements are certainly possible; for example, coverage of one and two doses of HPV vaccine in Scottish girls aged 14-15 years is $93 \%$ and $86 \%$, respectively [68]. Further increases in coverage rates, particularly in rates of completed vaccination, are achievable with a switch from a 3-dose to a 2-dose schedule.

Australia has been one of the leading countries in implementing public health programmes for the prevention of HPV, being among the first to introduce a National HPV Vaccination Programme for girls and young women and subsequently the first to expand eligibility for government-funded universal vaccination to boys. Inclusion of boys in the programme was considered vital for reasons of equity given the substantial disease burden in men, particularly MSM who would not benefit from a female-only vaccination programme, and the expected incremental reduction in HPV infections among women. A gender-neutral programme also assured the acceptability of the programme and allowed the prevention of HPV-associated cancer to be framed as an issue for all young people. The changes to the NCSP are an important advance in the prevention of HPV-associated disease. With continued improving vaccine uptake, Australia is moving towards elimination of vaccine-type HPV disease [69].

\section{Acknowledgements}

We would like to thank Ms Madeline Hall, Dr David Smith, Ms Karen Peterson, Dr Christine Selvey, Ms Sue Campbell-Lloyd, A/Prof Michelle Giles and Prof John Kaldor for providing comments on drafts of the manuscript. We would also like to thank Ms Rachel Linden, Ms Oriana Wallace and Ms Hope Peisley of the Immunisation Branch, Australian Government Department of Health, and Dr Clayton Chiu of NCIRS for their input into the preceding work that led to the development of this manuscript. We would like to thank Ms Catherine King for assistance in conducting literature searches, Mr Edward Jacyna for assistance in retrieval of documents and published articles, Ms Deepika Jindal for editorial assistance, and Ms Lyn Benfield from NCIRS for administrative support.
Funding/Support:

There was no specific funding for this study. The National Centre for Immunisation Research and Surveillance (NCIRS) receives support, either financial or otherwise, from the Australian Government Department of Health, New South Wales Department of Health, The Sydney Children's Hospital Network, and the University of Sydney, Australia. Helen Marshall and Basil Donovan acknowledge funding from NHMRC for Research Fellowships.

\section{Conflict of interest}

None declared. Helen Marshall, Julia Brotherton, Basil Donovan and Kristine Macartney are members of the Australian Technical Advisory Group on Immunisation's (ATAGl's) HPV Working Party (November 2014 to February 2018). This manuscript reflects the views of the authors only, and does not necessarily represent the views of ATAGI. Julia Brotherton and Basil Donovan have received funding for HPV-related research from manufacturers of HPV vaccines (Seqirus (JB and $B D$ ) and MSD (JB)) and the Australian Department of Health (BD). Helen Marshall's institution receives funding for vaccine trials sponsored by GlaxoSmithKline and Seqirus. No specific funding was provided for this review, and none of the co-authors receive any personal financial benefits from industry sponsors.

\section{Authors' contributions}

CP wrote the first draft of the manuscript. All authors contributed to the identification and interpretation of evidence included in this manuscript. All authors participated in drafting and revising the manuscript critically for intellectual content, and gave final approval to the version for submission.

\section{References}

1. Australian Institute of Health and Welfare (AIHW). Cervical screening in Australia 2018. Cat. no. CAN 111. Canberra: AlHW; 2018. Available from: https://www.aihw.gov.au/reports/ cancer-screening/cervical-screening-in-australia-2018/ contents/table-of-contents

2. Condon JR, Zhang X, Dempsey K, Garling L, Guthridge S. Trends in cancer incidence and survival for Indigenous and non-Indigenous people in the Northern Territory. Med J Aust. 2016;205(10):454-8. https://doi.org/10.5694/mja16.00588 PMID: 27852183

3. Jin F, Stein AN, Conway EL, Regan DG, Law M, Brotherton $J M$, et al. Trends in anal cancer in Australia, 1982-2005. Vaccine. 2011;29(12):2322-7. https://doi.org/10.1016/j. vaccine.2011.01.015 PMID: 21255682

4. Australian Institute of Health and Welfare (AIHW). Australian cancer incidence and mortality (ACIM) books: Anal cancer. Canberra: AlHW; 2016.

5. Machalek DA, Poynten M, Jin F, Fairley CK, Farnsworth A, Garland SM, et al. Anal human papillomavirus infection and associated neoplastic lesions in men who have sex with men: a systematic review and meta-analysis. Lancet Oncol. 2012;13(5):487-500. https://doi.org/10.1016/S14702045(12)70080-3 PMID: 22445259

6. Vajdic CM, van Leeuwen MT, Jin F, Prestage G, Medley G, Hillman RJ, et al. Anal human papillomavirus genotype diversity and co-infection in a community-based sample of homosexual men. Sex Transm Infect. 2009;85(5):330-5. https://doi.org/10.1136/sti.2008.034744 PMID: 19342375

7. Poynten IM, Tabrizi SN, Jin F, Templeton DJ, Machalek DA, Cornall A, et al. SPANC Study Team. Vaccine-preventable anal human papillomavirus in Australian gay and bisexual men. Papillomavirus Res. 2017;3:80-4. https://doi.org/10.1016/j. pvr.2017.02.003 PMID: 28720461

8. Grulich AE, Jin F, Conway EL, Stein AN, Hocking J. Cancers attributable to human papillomavirus infection. Sex Health. 
2010;7(3):244-52. https://doi.org/10.1071/SH10020 PMID: 20719211

9. Wakeham K, Kavanagh K. The burden of HPV-associated anogenital cancers. Curr Oncol Rep. 2014;16(9):402. https:// doi.org/10.1007/s11912-014-0402-4 PMID: 25118645

10. Condon JR, Rumbold AR, Thorn JC, O’Brien MM, Davy MJ, Zardawi I. A cluster of vulvar cancer and vulvar intraepithelial neoplasia in young Australian indigenous women. Cancer Causes Control. 2009;20(1):67-74. https://doi.org/10.1007/ S10552-008-9218-6 PMID: 18766449

11. Ariyawardana A, Johnson NW. Trends of lip, oral cavity and oropharyngeal cancers in Australia 1982-2008: overall good news but with rising rates in the oropharynx. BMC Cancer. 2013;13(1):333. https://doi.org/10.1186/1471-2407-13-333 PMID: 23829309

12. Hocking JS, Stein A, Conway EL, Regan D, Grulich A, Law M, et al. Head and neck cancer in Australia between 1982 and 2005 show increasing incidence of potentially HPV-associated oropharyngeal cancers. Br J Cancer. 2011;104(5):886-91. https://doi.org/10.1038/sj.bjc.6606091 PMID: 21285981

13. Hong A, Lee CS, Jones D, Veillard AS, Zhang M, Zhang X, et al. Rising prevalence of human papillomavirus-related oropharyngeal cancer in Australia over the last 2 decades. Head Neck. 2016;38(5):743-50. https://doi.org/10.1002/ hed.23942 PMID: 25521312

14. Elwood JM, Youlden DR, Chelimo C, Ioannides SJ, Baade PD. Comparison of oropharyngeal and oral cavity squamous cell cancer incidence and trends in New Zealand and Queensland, Australia. Cancer Epidemiol. 2014;38(1):16-21. https://doi. org/10.1016/j.canep.2013.12.004 PMID: 24445141

15. Chaturvedi AK, Anderson WF, Lortet-Tieulent J, Curado MP, Ferlay J, Franceschi S, et al. Worldwide trends in incidence rates for oral cavity and oropharyngeal cancers. J Clin Oncol. 2013;31(36):4550-9. https://doi.org/10.1200/JC0.2013.50.3870 PMID: 24248688

16. Chow EP, Danielewski JA, Fehler G, Tabrizi SN, Law MG, Bradshaw CS, et al. Human papillomavirus in young women with Chlamydia trachomatis infection 7 years after the Australian human papillomavirus vaccination programme: a cross-sectional study. Lancet Infect Dis. 2015;15(11):131423. https://doi.org/10.1016/S1473-3099(15)00055-9 PMID: 26201300

17. Tabrizi SN, Brotherton JML, Kaldor JM, Skinner SR, Cummins E, Liu B, et al. Fall in human papillomavirus prevalence following a national vaccination program. J Infect Dis. 2012;206(11):164551. https://doi.org/10.1093/infdis/jis590 PMID: 23087430

18. Tabrizi SN, Brotherton JM, Kaldor JM, Skinner SR, Liu B, Bateson D, et al. Assessment of herd immunity and crossprotection after a human papillomavirus vaccination programme in Australia: a repeat cross-sectional study. Lancet Infect Dis. 2014;14(10):958-66. https://doi.org/10.1016/S14733099(14)70841-2 PMID: 25107680

19. Osborne SL, Tabrizi SN, Brotherton JM, Cornall AM, Wark JD, Wrede CD, et al. VACCINE Study group. Assessing genital human papillomavirus genoprevalence in young Australian women following the introduction of a national vaccination program. Vaccine. 2015;33(1):201-8. https://doi.org/10.1016/j. vaccine.2014.10.045 PMID: 25444787

20. Tabrizi SN, Brotherton JM, Stevens MP, Condon JR, McIntyre $P$, Smith D, et al. WHINURS group. HPV genotype prevalence in Australian women undergoing routine cervical screening by cytology status prior to implementation of an HPV vaccination program. J Clin Virol. 2014;60(3):250-6. https://doi. org/10.1016/j.jcv.2014.04.013 PMID: 24854516

21. Machalek DA, Garland SM, Brotherton JML, Bateson D, McNamee K, Stewart M, et al. Very low prevalence of vaccine human papillomavirus types among 18- to 35-year old Australian women 9 years following implementation of vaccination. J Infect Dis. 2018;217(10):1590-600. https://doi. org/10.1093/infdis/jiy075 PMID: 29425358

22. Drolet M, Bénard É, Boily MC, Ali H, Baandrup L, Bauer H, et al. Population-level impact and herd effects following human papillomavirus vaccination programmes: a systematic review and meta-analysis. Lancet Infect Dis. 2015;15(5):565 8o. https://doi.org/10.1016/S1473-3099(14)71073-4 PMID: 25744474

23. Chow EPF, Machalek DA, Tabrizi SN, Danielewski JA, Fehler $\mathrm{G}$, Bradshaw CS, et al. Quadrivalent vaccine-targeted human papillomavirus genotypes in heterosexual men after the Australian female human papillomavirus vaccination programme: a retrospective observational study. Lancet Infect Dis. 2017;17(1):68-77. https://doi.org/10.1016/S14733099(16)30116-5 PMID: 27282422

24. Pillsbury AJ, Quinn HE, Evans TD, McIntyre PB, Brotherton JML. Population-level herd protection of males from a female human papillomavirus vaccination program: evidence from Australian serosurveillance. Clin Infect Dis. 2017;65(5):827-32. https:// doi.org/10.1093/cid/cix436 PMID: 29017279

25. Australian Institute of Health and Welfare (AIHW). Cervica screening in Australia 2013-2014. Cancer series no. 97. Cat. no. CAN 95. Canberra: AlHW; 2016.

26. Gertig DM, Brotherton JM, Budd AC, Drennan K, Chappell G, Saville AM. Impact of a population-based HPV vaccination program on cervical abnormalities: a data linkage study. BMC Med. 2013;11(1):227. https://doi.org/10.1186/1741-7015-11-227 PMID: 24148310

27. Brotherton JML, Malloy M, Budd AC, Saville M, Drennan KT, Gertig DM. Effectiveness of less than three doses of quadrivalent human papillomavirus vaccine against cervical intraepithelial neoplasia when administered using a standard dose spacing schedule: Observational cohort of young women in Australia. Papillomavirus Research.2015;1:59-73. https:// doi.org/10.1016/j.pvr.2015.05.005

28. Crowe E, Pandeya N, Brotherton JM, Dobson AJ, Kisely S, Lambert SB, et al. Effectiveness of quadrivalent human papillomavirus vaccine for the prevention of cervical abnormalities: case-control study nested within a population based screening programme in Australia. BMJ. 2014;348(maro4 2):g1458. https://doi.org/10.1136/bmj.g1458 PMID: 24594809

29. Smith MA, Liu B, McIntyre P, Menzies R, Dey A, Canfell K. Fall in genital warts diagnoses in the general and indigenous Australian population following implementation of a national human papillomavirus vaccination program: analysis of routinely collected national hospital data. J Infect Dis. 2015;211(1):91-9. https://doi.org/10.1093/infdis/jiu370 PMID: 25117753

30. Drolet M, Laprise JF, Brotherton IML, Donovan B, Fairley CK, Ali $\mathrm{H}$, et al. The impact of human papillomavirus catch-up vaccination in Australia: implications for introduction of multiple age cohort vaccination and postvaccination data interpretation. J Infect Dis. 2017;216(10):1205-9. https://doi. org/10.1093/infdis/jix476 PMID: 28968800

31. Fairley CK, Hocking JS, Gurrin LC, Chen MY, Donovan B, Bradshaw CS. Rapid decline in presentations of genital warts after the implementation of a national quadrivalent human papillomavirus vaccination programme for young women. Sex Transm Infect. 2009;85(7):499-502. https://doi.org/10.1136/ sti.2009.037788 PMID: 19837728

32. Donovan B, Franklin N, Guy R, Grulich AE, Regan DG, Ali H, et al. Quadrivalent human papillomavirus vaccination and trends in genital warts in Australia: analysis of national sentinel surveillance data. Lancet Infect Dis. 2011;11(1):39-44. https:// doi.org/10.1016/S1473-3099(10)70225-5 PMID: 21067976

33. Read TRH, Hocking JS, Chen MY, Donovan B, Bradshaw CS, Fairley CK. The near disappearance of genital warts in young women 4 years after commencing a national human papillomavirus (HPV) vaccination programme. Sex Transm Infect. 2011;87(7):544-7. https://doi.org/10.1136/ sextrans-2011-050234 PMID: 21970896

34. Ali H, Donovan B, Wand H, Read TR, Regan DG, Grulich AE, et al. Genital warts in young Australians five years into national human papillomavirus vaccination programme: national surveillance data. BMJ. 2013;346(apr18 1):f2032. https://doi. org/10.1136/bmj.f2032 PMID: 23599298

35. Ali H, Guy RJ, Wand H, Read TR, Regan DG, Grulich AE, et al. Decline in in-patient treatments of genital warts among young Australians following the national HPV vaccination program. BMC Infect Dis. 2013;13(140):140. https://doi. org/10.1186/1471-2334-13-140 PMID: 23506489

36. Chow EPF, Read TRH, Wigan R, Donovan B, Chen MY, Bradshaw CS, et al. Ongoing decline in genital warts among young heterosexuals 7 years after the Australian human papillomavirus (HPV) vaccination programme. Sex Transm Infect. 2015;91(3):214-9. https://doi.org/10.1136/ sextrans-2014-051813 PMID: 25305210

37. Ali H, McManus H, O’Connor CC, Callander D, Kong M, Graham $S$, et al. Human papillomavirus vaccination and genital warts in young Indigenous Australians: national sentinel surveillance data. Med J Aust. 2017;206(5):204-9. https://doi.org/10.5694/ mja16.00597 PMID: 28301790

38. Larson DA, Derkay CS. Epidemiology of recurrent respiratory papillomatosis. APMIS. 2010;118(6-7):450-4. https://doi. org/10.1111/j.1600-0463.2010.02619.x PMID: 20553527

39. Novakovic D, Cheng ATL, Zurynski Y, Booy R, Walker PJ, Berkowitz R, et al. A prospective study of the incidence of juvenile-onset recurrent respiratory papillomatosis after implementation of a national HPV vaccination program. J Infect Dis. 2018;217(2):208-12. PMID: 29136168

40. Brotherton JML, Tabrizi SN, Phillips S, Pyman J, Cornall AM, Lambie N, et al. Looking beyond human papillomavirus (HPV) genotype 16 and 18: Defining HPV genotype distribution in cervical cancers in Australia prior to vaccination. Int J Cancer. 
2017;141(8):1576-84. https://doi.org/10.1002/ijc.30871 PMID: 28677147

41. Baricevic I, He X, Chakrabarty B, Oliver AW, Bailey C, Summers J, et al. High-sensitivity human papilloma virus genotyping reveals near universal positivity in anal squamous cell carcinoma: different implications for vaccine prevention and prognosis. Eur J Cancer. 2015;51(6):776-85. https://doi. org/10.1016/j.ejca.2015.01.058 PMID: 25702585

42. Hillman RJ, Garland SM, Gunathilake MPW, Stevens M, Kumaradevan N, Lemech C, et al. Human papillomavirus (HPV) genotypes in an Australian sample of anal cancers. Int J Cancer. 2014;135(4):996-1001. https://doi.org/10.1002/ ijc.28730 PMID: 24497322

43. De Vuyst H, Clifford GM, Nascimento MC, Madeleine MM, Franceschi S. Prevalence and type distribution of human papillomavirus in carcinoma and intraepithelial neoplasia of the vulva, vagina and anus: a meta-analysis. Int J Cancer. 2009;124(7):1626-36. https://doi.org/10.1002/ijc.24116 PMID: 19115209

44. Saraiya M, Unger ER, Thompson TD, Lynch CF, Hernandez BY, Lyu CW, et al. HPV Typing of Cancers Workgroup. US assessment of HPV types in cancers: implications for current and 9-valent HPV vaccines. J Natl Cancer Inst. 2015;107(6):djv086. https://doi.org/10.1093/jnci/djvo86 PMID: 25925419

45. Antonsson A, Neale RE, Boros S, Lampe G, Coman WB, Pryor DI, et al. Human papillomavirus status and p16(INK4A) expression in patients with mucosal squamous cell carcinoma of the head and neck in Queensland, Australia. Cancer Epidemiol. 2015;39(2):174-81. https://doi.org/10.1016/j. canep.2015.01.010 PMID: 25677091

46. Simms KT, Hall M, Smith MA, Lew J-B, Hughes S, Yuill S, et al. Optimal management strategies for primary HPV testing for cervical screening: cost-effectiveness evaluation for the National Cervical Screening Program in Australia. PLoS One. 2017;12(1):e0163509. https://doi.org/10.1371/journal. pone.0163509 PMID: 28095411

47. Simms KT, Smith MA, Lew JB, Kitchener HC, Castle PE, Canfell $\mathrm{K}$. Will cervical screening remain cost-effective in women offered the next generation nonavalent HPV vaccine? Results for four developed countries. Int J Cancer. 2016;139(12):27718o. https://doi.org/10.1002/ijc.30392 PMID: 27541596

48. Simms KT, Laprise J-F, Smith MA, Lew J-B, Caruana M, Brisson $M$, et al. Cost-effectiveness of the next generation nonavalent human papillomavirus vaccine in the context of primary human papillomavirus screening in Australia: a comparative modelling analysis. Lancet Public Health. 2016;1(2):e66-75. https://doi. org/10.1016/S2468-2667(16)30019-6 PMID: 29253419

49. Korostil IA, Ali H, Guy RJ, Donovan B, Law MG, Regan DG. Near elimination of genital warts in Australia predicted with extension of human papillomavirus vaccination to males. Sex Transm Dis. 2013;40(11):833-5. https://doi.org/10.1097/ OLQ.0000000000000030 PMID: 24113401

50. Brotherton JML, Zuber PLF, Bloem PJN. Primary prevention of HPV through vaccination: update on the current global status. Curr Obstet Gynecol Rep. 2016;5(3):210-24. https://doi. org/10.1007/s13669-016-0165-z

51. Mesher D, Panwar K, Thomas SL, Edmundson C, Choi YH, Beddows S, et al. The impact of the National HPV Vaccination Program in England using the bivalent HPV vaccine: surveillance of type-specific HPV in young females, 20102016. J Infect Dis. 2018;218(6):911-21. https://doi.org/10.1093/ infdis/jiy249 PMID: 29917082

52. Carozzi FM, Ocello C, Burroni E, Faust H, Zappa M, Paci E, et al. Effectiveness of HPV vaccination in women reaching screening age in Italy. J Clin Virol. 2016;84:74-81. https://doi. org/10.1016/j.jcv.2016.09.011 PMID: 27728850

53. Feiring B, Laake I, Christiansen IK, Hansen M, Stålcrantz J, Ambur $\mathrm{OH}$, et al. Substantial decline in prevalence of vaccinetype and non-vaccine type HPV in vaccinated and unvaccinated girls 5 years after implementing HPV vaccine in Norway. J Infect Dis. 2018. https://doi.org/10.1093/infdis/jiy432 PMID: 30010913

54. Jeannot E, Viviano M, de Pree C, Amadane M, Kabengele E, Vassilakos $P$, et al. Prevalence of vaccine type infections in vaccinated and non-vaccinated young women: HPV-IMPACT, a self-sampling study. Int J Environ Res Public Health. 2018;15(7):E1447. https://doi.org/10.3390/ijerph15071447 PMID: 29987255

55. Herweijer E, Ploner A, Sparén P. Substantially reduced incidence of genital warts in women and men six years after HPV vaccine availability in Sweden. Vaccine. 2018;36(15):191720. https://doi.org/10.1016/j.vaccine.2018.02.097 PMID: 29523448

56. Dominiak-Felden G, Gobbo C, Simondon F. Evaluating the early benefit of quadrivalent HPV vaccine on genital warts in Belgium: a cohort study. PLoS One. 2015;10(7):e0132404. https://doi.org/10.1371/journal.pone.0132404 PMID: 26147096

57. Pollock KG, Kavanagh K, Potts A, Love J, Cuschieri K, Cubie H, et al. Reduction of low- and high-grade cervical abnormalities associated with high uptake of the HPV bivalent vaccine in Scotland. Br J Cancer. 2014;111(9):1824-30. https://doi. org/10.1038/bjc.2014.479 PMID: 25180766

58. Joura EA, Giuliano AR, Iversen OE, Bouchard C, Mao C, Mehlsen J, et al. Broad Spectrum HPV Vaccine Study. A 9-valent HPV vaccine against infection and intraepithelial neoplasia in women. N Engl J Med. 2015;372(8):711-23. https://doi. org/10.1056/NEJMoa1405044 PMID: 25693011

59. Moreira ED Jr, Block SL, Ferris D, Giuliano AR, Iversen O-E, Joura EA, et al. Safety profile of the 9 -valent HPV vaccine: a combined analysis of 7 phase III clinical trials. Pediatrics. 2016;138(2):e20154387. https://doi.org/10.1542/peds.2015 4387 PMID: 27422279

6o. Cuschieri K, Kavanagh K, Moore C, Bhatia R, Love J, Pollock KG. Impact of partial bivalent HPV vaccination on vaccinetype infection: a population-based analysis. Br J Cancer. 2016;114(11):1261-4. https://doi.org/10.1038/bjc.2016.97 PMID: 27115467

61. Kreimer AR, Struyf F, Del Rosario-Raymundo MR, Hildesheim A, Skinner SR, Wacholder S, et al. Costa Rica Vaccine Trial Study Group AuthorsPATRICIA Study Group AuthorsHPV PATRICIA Principal Investigators/Co-Principal Investigator CollaboratorsGSK Vaccines Clinical Study Support Group. Efficacy of fewer than three doses of an HPV-16/18 ASo4adjuvanted vaccine: combined analysis of data from the Costa Rica Vaccine and PATRICIA Trials. Lancet Oncol. 2015;16(7):77586. https://doi.org/10.1016/S1470-2045(15)00047-9 PMID: 26071347

62. Zhai L, Tumban E. Gardasil-9: A global survey of projected efficacy. Antiviral Res. 2016;130:101-9. https://doi. org/10.1016/j.antiviral.2016.03.016 PMID: 27040313

63. World Health Organization. Human papillomavirus vaccines: WHO position paper, May 2017. Wkly Epidemiol Rec. 2017;92(19):241-68. PMID: 28530369

64. Brotherton JM, Winch KL, Bicknell L, Chappell G, Saville M. HPV vaccine coverage is increasing in Australia. Med J Aust. 2017;206(6):262. https://doi.org/10.5694/mja16.00958 PMID: 28359009

65. Brotherton JM, Murray SL, Hall MA, Andrewartha LK, BankS CA, Meijer D, et al. Human papillomavirus vaccine coverage among female Australian adolescents: success of the schoolbased approach. Med J Aust. 2013;199(9):614-7. https://doi. org/10.5694/mja13.10272 PMID: 24182228

66. Marshall H, Ryan P, Roberton D, Baghurst P. A cross-sectional survey to assess community attitudes to introduction of Human papillomavirus vaccine. Aust N Z J Public Health. 2007;31(3):235-42. https://doi.org/10.1111/j.1467842X.2007.00054.x PMID: 17679241

67. Marshall HS, Collins J, Sullivan T, Tooher R, O’Keefe M, Skinner SR, et al. Parental and societal support for adolescent immunization through school based immunization programs. Vaccine. 2013;31(30):3059-64. https://doi.org/10.1016/j. vaccine.2013.04.064 PMID: 23664996

68. National Statistics. HPV immunisation statistics Scotland school year 2015/16. Glasgow: National Services Scotland; 2016. Available from: https://www.isdscotland.org/HealthTopics/Child-Health/Publications/2016-11-08/2016-11-08-HPVImmunisation-Report.pdf

69. Brisson M, Bénard É, Drolet M, Bogaards JA, Baussano I, Vänskä S, et al. Population-level impact, herd immunity, and elimination after human papillomavirus vaccination: a systematic review and meta-analysis of predictions from transmission-dynamic models. Lancet Public Health. 2016;1(1):e8-17. https://doi.org/10.1016/S24682667(16)30001-9 PMID: 29253379

70. Stevens MP, Garland SM, Tan JH, Quinn MA, Petersen RW, Tabrizi SN. HPV genotype prevalence in women with abnormal pap smears in Melbourne, Australia. J Med Virol. 2009;81(7):1283-91. https://doi.org/10.1002/jmv.21515 PMID: 19475612

71. Garland SM, Brotherton JML, Skinner SR, Pitts M, Saville $M$, Mola G, et al. Human papillomavirus and cervical cancer in Australasia and Oceania: risk-factors, epidemiology and prevention. Vaccine. 2008;26(Suppl 12):M80-8. https://doi. org/10.1016/j.vaccine.2008.05.041 PMID: 18945417

72. Callegari ET, Tabrizi SN, Pyman J, Saville M, Cornall AM, Brotherton JM, et al. How best to interpret mixed human papillomavirus genotypes in high-grade cervical intraepithelial neoplasia lesions. Vaccine. 2014;32(32):4082-8. https://doi. org/10.1016/j.vaccine.2014.05.041 PMID: 24857693 
73. Antonsson A, Wilson LF, Kendall BJ, Bain CJ, Whiteman

DC, Neale RE. Cancers in Australia in 2010 attributable to

infectious agents. Aust N Z J Public Health. 2015;39(5):446-51.

https://doi.org/10.1111/1753-6405.12445 PMID: 26437730

74. Australian Institute of Health and Welfare (AIHW). Cancer

in Australia: an overview, 2012. Canberra: AlHW; 2012.

Available from; https://www.aihw.gov.au/reports/

cancer/cancer-in-australia-an-overview-2012/contents/

table-of-contents

75. Australian institute of Health and Welfare (AIHW).

Gynaecological cancers in Australia: an overview. Canberra:

AlHW; 2012. Available from: https://www.aihw.gov.au/reports/ cancer/gynaecological-cancers-in-australia-an-overview/ contents/summary

\section{License and copyright}

This is an open-access article distributed under the terms of the Creative Commons Attribution (CC BY 4.0) Licence. You may share and adapt the material, but must give appropriate credit to the source, provide a link to the licence, and indicate if changes were made.

This article is copyright of the authors, 2018. 